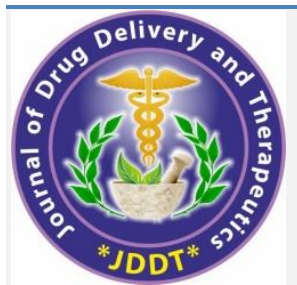

Open

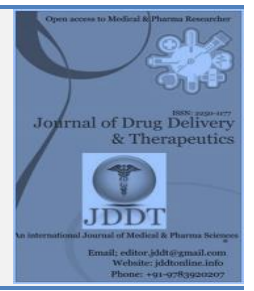

Research Article

\title{
The Relationship Between Platelet Count and Severity of Dengue Hemorrhagic Fever in Pediatric Patients at UKI Cawang Hospital for the period January 2015-December 2015
}

\author{
Vidi Posdo A. Simarmata, Ida Bagus Eka Utama Wija, Ronny
}

Medical Faculty, Universitas Kristen Indonesia, Jakarta, Indonesia

\begin{tabular}{ll}
\hline Article Info: \\
\end{tabular}

\section{Cite this article as:}

Simarmata VPA, Wija IBEU, Ronny, The Relationship Between Platelet Count and Severity of Dengue Hemorrhagic Fever in Pediatric Patients at UKI Cawang Hospital for the period January 2015December 2015, Journal of Drug Delivery and Therapeutics. 2021; 11(6):75-80

DOI: http://dx.doi.org/10.22270/jddt.v11i6.5044

\begin{abstract}
This thesis discusses the connection of platelet number and the severity of dengue hemorrhagic fever in pediatric patients in Cawang UKI Hospital from January 2015 to December 2015. The data were collected from medical records. This research is a retrospective cross-sectional method. Total population of 170 and take a sample of 119 cases. From that, samples obtained from platelet amount decreased with increasing severity of dengue hemorrhagic fever, there is a significant connection between platelet count decreases with severity of dengue hemorrhagic fever with $p=0.000$.
\end{abstract}

Keywords: platelets, the severity of dengue hemorrhagic fever

\footnotetext{
*Address for Correspondence:
}

Vidi Posdo A. Simarmata, Medical Faculty, Universitas Kristen Indonesia, Jakarta, Indonesia

\section{INTRODUCTION}

Dengue fever (DD) is a clinical syndrome caused by the dengue virus, characterized by biphasic fever, myalgia or arthralgia, rash, leukopenia, and lymphadenopathy. Dengue hemorrhagic fever (DHF) is a clinical manifestation that is more severe than DD, which is also caused by the dengue virus. Dengue fever is found in tropical and subtropical areas. Dengue virus is transmitted by mosquitoes of the Stegomyia family, the main vectors of which are Aedes aegypti and Aedes albopictus. ${ }^{1}$ According to WHO, more than $70 \%( \pm 1.8$ million) of the population at risk of dengue virus are in Southeast Asia and Western Pacific regions. Dengue outbreaks are a significant public health problem in Indonesia, Myanmar, Sri Lanka, Thailand, and Timor Leste. ${ }^{1 ; 2}$

In 1968 in Indonesia, dengue infection was reported for the first time, and 58 cases in DKI Jakarta and Surabaya (24 cases died). The highest dengue cases in Indonesia occurred in 2007 , with 150,000 cases with more than 25,000 cases originating from Jakarta and West Java. ${ }^{2}$ Every year, the number of dengue cases in Indonesia has always been an Extraordinary Event (KLB) in several provinces. The most significant incident occurred in 1998 and 2004, with 79,480 cases and more than 800 deaths. $^{3}$

Pathophysiological mechanisms between DD and DHF are different so that the clinical manifestations of both are different. The main difference is the presence of a typical shock in DHF caused by plasma leakage, which is thought to occur due to an immunological process. ${ }^{2,3}$ Clinically, DHF is divided into four grades. Grades 1 and 2 are classified as DHF, while grades 3 and 4 are classified as dengue shock syndrome (SSD). ${ }^{4}$ The average platelet count is 150,000 $450,000 / \mu \mathrm{l}$. Thrombocytopenia occurs when the platelet count is less than the lower limit of the reference value $(<150,000 / \mu l)$. Thrombocytopenia that occurs in cases of DHF $(\leq 100,000 / 1)$ is caused by the formation of a viral antibody complex that stimulates platelet aggregation, and then the aggregate passes through the reticulum endoplasmic cell (RES) so that it is destroyed.5,6 Based on the description of the background above, the authors wanted to find out whether there was a relationship between the decreased platelet count and the severity of DHF at the Cawang UKI Hospital. Based on this background, the problem formulation answered in this study is: "Is there a relationship between the reduced number of platelets and the severity of DHF?" with the aim is to determine the effect of platelet count on the severity of dengue hemorrhagic fever.

\section{LITERATURE REVIEW}

Dengue hemorrhagic fever (DHF) is an infectious disease caused by the dengue virus and transmitted by the Aedes 
aegypti mosquito, which is characterized by a sudden fever of 2 to 7 days without a clear cause, weakness/lethargy, restlessness, heartburn, accompanied by signs of bleeding on the skin, bleeding spots (petechiae), bruising (ecchymosis), or a rash. Sometimes accompanied by nosebleeds, bloody stools, vomiting blood, decreased consciousness or shock (shock). ${ }^{7}$

Aedes aegypti is a type of mosquito that can carry the dengue virus, the cause of dengue fever. This mosquito is a mosquito that has a high affinity for biting humans (anthropophilic). Only female mosquitoes bite humans and bite more than one individual (multiple-bite) to meet their nutritional needs. This lifestyle causes the mosquito to become a vector that can transmit the dengue virus from one individual to another. ${ }^{8}$ Adult Aedes aegypti is smaller than the house mosquito (Culex qunquefasciatus), has a black base colour with white spots on the body, especially on the legs and is known for its distinctive morphological shape as a mosquito that has a lire-like appearance. form) which is white on the back (mesonotum), i.e. there are two vertical curved lines on the left and right. ${ }^{8}$

The development from egg to mosquito is approximately 9 to 10 days. Each time they lay eggs, the female mosquito can release as many as 100 eggs. Aedes aegypti mosquito eggs are black with a size of $\pm 0.80 \mathrm{~mm}$, can survive in a dry place (without water) for up to 6 months. After \pm two days after being submerged in water, the eggs will hatch into larvae, and then the larvae will grow to reach $0.5-1 \mathrm{~cm}$. Aedes aegypti mosquito larvae always move actively in the water, from the bottom to the top of the water surface, breathe and then come back down, and so on. After 6 to 8 days, the larvae will develop into pupae. The cocoons are comma-shaped and move slowly. 1 to 2 days after that, the pupae turn into adult mosquitoes. ${ }^{8,9}$

Dengue fever (DD) and dengue hemorrhagic fever (DHF) are caused by the dengue virus, which belongs to the Flavivirus genus of the Flaviviridae family. Flavivirus is a virus with a diameter of $30 \mathrm{~nm}$ consisting of single-chain ribonucleic acid (RNA) with a molecular weight of $4 \times 106$. There are four serotypes of the dengue virus, namely DEN-1, DEN-2, DEN-3, and DEN-4, all of which can cause DD or DENV dengue. Among the four serotypes, DEN-3 is most commonly found in Indonesia. ${ }^{8}$

Transmission of the dengue virus depends on abiotic and biotic factors. Biotic factors are viral, mosquito vectors, and human hosts: while abiotic factors are environmental temperature, humidity, and rainfall. Global climate change is reported to make mosquitoes dehydrated so that to defend themselves mosquitoes will bite humans more often. The increase in rainfall, especially during the dry season to the rainy season, has been reported to affect the increase in dengue cases. Population density, population mobility, and environmental health also play a role in spreading the dengue virus. ${ }^{9}$

The mechanism of the occurrence of DHF is still being debated. Based on available data, there is strong evidence showing that immunopathological mechanisms play a role in the occurrence of DHF and dengue shock syndrome (SSD). Immune responses that are known to play a role in the pathogenesis of DHF are 7,10 : a) Humoral response in the form of antibody formation that plays a role in virus neutralization, complement-mediated cytolysis, and antibody-mediated cytotoxicity. Antibodies to the dengue virus play a role in accelerating viral replication in monocytes or macrophages. This hypothesis is called antibody-dependent enhancement (ADE); b) T-helper (CD4) and T-cytotoxic (CD8) $\mathrm{T}$ lymphocytes play a role in the cellular immune response against the dengue virus. T-helper differentiation, namely Th1, will produce interferon-gamma, IL-2, and lymphokines: while Th2 will produce IL-4, IL-5, IL6 , and IL-10; c) Monocytes and macrophages play a role in viral phagocytosis by antibody opsonization. However, this phagocytosis process causes an increase in viral replication and cytokine secretion by macrophages. Kuranne and Ennis, in 1994, summarized the opinion of Halstead and other researchers: stated that dengue virus infection causes the activation of macrophages that phagocytize non-neutralizing virus-antibody complexes so that the virus replicates in macrophages. The occurrence of macrophage infection by the dengue virus causes activation of T-helper and Tcytotoxic so that lymphokines and interferon-gamma are produced. Interferon-gamma will activate monocytes so that various inflammatory mediators are secreted such as TNF-, IL-1, Platelet-activating factor (PAF), IL-6, and histamine resulting in endothelial cell dysfunction and plasma leakage; d) Activation of the complement system by immune complexes causes the formation of $\mathrm{C} 3 \mathrm{a}$ and $\mathrm{C} 5 \mathrm{a}$ which also results in plasma leakage.

Thrombocytopenia in dengue infection occurs through the mechanism of bone marrow suppression, destruction, and shortening of platelet life span. Bone marrow appearance at the beginning of infection ( $<5$ days) shows a hypocellular state and suppression of megakaryocytes. After the nadir is reached, there will be an increase in the process of hematopoiesis, including megakaryopoiesis. Thrombopoietin levels in the blood at the time of thrombocytopenia show an increase, and this indicates that there is stimulation of thrombopoiesis as a compensatory mechanism for thrombocytopenia. Platelet destruction occurs through the binding of $\mathrm{C} 3 \mathrm{~g}$ fragments, the presence of dengue virus antibodies, consumption of platelets during the coagulopathy process and sequestration in the periphery. Impaired platelet function occurs through the mechanism of impaired ADP release, increased levels of -thrombomodulin, and PF4, which is a sign of platelet degranulation.2,11

Coagulopathy occurs as a result of viral interactions with the endothelium causing endothelial dysfunction. Various studies have shown that consumptive coagulopathy occurs in stage III and IV dengue hemorrhagic fever. Activation of coagulation in dengue hemorrhagic fever occurs through activation of the extrinsic pathway (tissue factor pathway). The intrinsic pathway also plays a role in activating factor XIa but not through contact activation (kallikrein C1inhibitor complex). ${ }^{11}$

The pathophysiology of DHF is a complex matter. Clinical symptoms that appear are based on a person's immune response. The theory that is currently used to explain the process of dengue virus infection is secondary heterologous infection. This theory explains that infection with one serotype of dengue virus will give the body long immunity to the virus, while the second/subsequent infection by viruses with different serotypes will appear as DHF and SSD. ${ }^{12}$

In DHF and DSS, an acute increase in vascular permeability is the primary pathophysiology. It will lead to plasma leakage into the extravascular space, resulting in hemoconcentration and a decrease in blood pressure. In severe cases, plasma volume decreases by more than $20 \%$, including pleural effusion, hemoconcentration and hypoproteinemia. Significant vascular destructive lesions do not occur.8,12

Three factors cause hemostatic changes in DHF and DSS: vascular changes, thrombocytopenia, and coagulation disorders, and almost all dengue patients have increased vascular fragility and thrombocytopenia, as well as an abnormal coagulogram. Dengue virus infection causes 
humoral and cellular immune responses, including antineutralization, anti-hemagglutinin, anti-complement. Antibodies that appear in general are IgG and IgM, starting to appear in primary and secondary infection, levels have increased.2

On the fifth day of fever, antibodies can be found in the blood, increasing in the first week to the third week and disappearing after 60-90 days. In primary infection, IgG antibodies increase on the 14th day of fever, while in secondary infection, IgG levels increase on the second day. Therefore, the diagnosis of primary infection is established by detecting IgM antibodies after the fifth day of illness, whereas in secondary infections, the diagnosis can be made earlier. $^{2}$

In primary infection, neutralizing antibodies recognize protein $\mathrm{E}$ and monoclonal antibodies against the dengue virus's NS1, PrM and NS3 (viral components), resulting in neutralization activity or complement activation so that virus-infected cells become infected lysed. This process eliminates many viruses, and the patient recovers by having immunity to the same virus serotype. If the patient is infected for the second time with a different serotype of the dengue virus, the dengue virus will act as a superantigen after being phagocytosed by macrophages or monocytes. These macrophages will display Antigen Presenting Cell (APC). 2,13

These antigens carry a specific polypeptide load derived from the Major Histocompatibility Complex (MHC II). Antigens containing MHC II peptides will bind to CD4+ (TH-1 and $\mathrm{TH}-2$ ) through $\mathrm{T}$ Cell Receptors (TCR) as a reaction to infection. Then TH-1 lymphocytes will release immunomodulatory substances, namely INF $\gamma$, IL-2, and Colony Stimulating Factor (CSF). IFN $\gamma$ will stimulate macrophages to secrete IL-1 and TNF $\alpha$. Interleukin-1 (IL-1) has an effect on endothelial cells, forms prostaglandins, and stimulates the expression of intercellular adhesion molecule 1 (ICAM 1). $\cdot, 10$

Colony Stimulating Factor (CSF) will stimulate neutrophils. By the influence of ICAM-1, neutrophils that CSF has stimulated will adhere to endothelial cells and release lysozyme, which makes endothelial walls lysis and endothelial open. Neutrophils also carry superoxide, which will affect oxygenation in mitochondria and the GMPs cycle, so that the endothelium becomes necrotic and causes vascular disorders [7]. Antigens containing MHC-1 will be expressed on the surface of the virus so that they are recognized by CD8+ $\mathrm{T}$ lymphocytes which are cytolytic, so that destroy all cells containing the virus and finally secreted IFN $\gamma$ and TNF $\alpha{ }^{1,14}$ Clinical manifestations that occur in dengue virus infection vary, depending on the degree of severity.

Dengue Fever-After the incubation period (4-6 days), symptoms such as fever, myalgia, backache (breakbone fever), and other non-specific constitutional symptoms such as malaise, anorexia and taste disturbances appear. Generally, fever arises sharp, continuous, biphasic (on the third day, the temperature drops but is still above average, then the temperature rises again), and lasts for 2-7 days. Other symptoms that can be encountered are arthralgia, vomiting, photophobia, retroorbital pain, indigestion, and abdominal pain. Laboratory examinations showed typical values, but in some cases, leukocytosis or leukopenia may occur. Platelet counts can be normal or decreased, but rarely less than $50,000 / \mathrm{mm} 3$.

Dengue Hemorrhagic Fever-DHF clinical manifestations begin with acute fever, continuous, sometimes biphasic, lasting 2-7 days. Fever may be accompanied by facial flushing, anorexia, myalgia, arthralgia, epigastric pain, nausea, vomiting, sore throat, and redness of the pharynx and conjunctiva. Bleeding manifestations may include a positive tourniquet test, spontaneous petechiae in the extremities, axillae, face, soft palate; epistaxis, bleeding gums or gastrointestinal bleeding. ${ }^{15}$ The clinical manifestations of DHF consist of three phases: the fever phase, the critical phase (the shock phase), and the healing phase (the convalescent phase).

Dengue Shock Syndrome-SSD is a hypovolemic shock that occurs in DHF, caused by increased capillary permeability accompanied by plasma leakage. Dengue shock generally occurs when the body temperature drops (critical phase), i.e. on the 4-5th sick day (range 3-7), and is often preceded by warning signs. Patients who do not receive adequate intravenous fluids will immediately go into shock.

Dengue Classification-Dengue fever is defined if there is acute fever, headache, retroorbital pain, myalgia, arthralgia, rash, and the presence of bleeding manifestations. Based on the degree of severity, dengue hemorrhagic fever (DHF) is classified into 4. The diagnosis of dengue infection can be established by16: History-Anamnesis usually results in the fever that occurs suddenly (acute) and is continuous. There are also other symptoms such as nausea, vomiting, muscle complaints such as myalgia, and decreased appetite. Physical Examination-Physical examination, which is mainly carried out, examines vital signs, such as pulse rate, blood pressure, body temperature, and respiratory rate. You can also check for signs of bleeding such as a positive tourniquet test (+), petechiae, epistaxis, bleeding gums and hematemesis/melena. On examination of the liver will be found enlarged liver (hepatomegaly).2,7 In shock, there is usually tachycardia (increased pulse rate), poor peripheral perfusion with cold acral manifestations, pulse pressure (systolic and diastolic difference) $<20 \mathrm{mmHg}$, or hypotension. In a state of shock, the blood pressure is no longer measurable, and the pulse is not palpable.7,17

Platelets are one of the essential components in the hemostatic system, produced in the bone marrow through cytoplasmic fragmentation in megakaryocytes. The average platelet count is $100-400 \times 109 / \mathrm{L}$. The condition in which the number of platelets increases is called thrombocytosis, while the number of platelets decreases is called thrombocytopenia. The primary function of platelets is to form a mechanical plug which is a normal hemostatic response to vascular injury. 18,19

In the absence of platelets, spontaneous leakage of blood can occur through the fine vessels (capillaries). In the case of DHF, the platelet value begins to decrease in the febrile phase and will reach its lowest point during the toxic/poisonous phase. Thrombocytopenia in dengue infection occurs due to the mechanism of bone marrow suppression, destruction and shortening of platelet life span. The cause of thrombocytopenia in DHF is the formation of a viral antibody complex that stimulates platelet aggregation. 3,20

\section{RESEARCH METHOD}

This research is a retrospective correlational study with a cross-sectional technique, carried out by collecting medical record data from January 2015 to December 2015, which aims to observe the relationship between platelet count and the severity of dengue hemorrhagic fever. This research was conducted from December 2016 to January 2017 at the Cawang UKI Hospital. The population in this study were pediatric patients with dengue hemorrhagic fever who met 
the diagnostic criteria at the Cawang UKI Hospital in 2015 as many as 170 people. The sample in this study was medical record data of pediatric patients diagnosed with dengue hemorrhagic fever. The data needed are clinical symptoms and laboratory test results. In this study, 119 samples met the research criteria (inclusion data). Data processing is done through the process of editing, coding, data entry, and cleaning. The data that has been obtained from the data collection process is simplified into the form of tables. The data processing used in this study is univariate and bivariate analysis (chi-square and correlation coefficient R), which analyses one variable to determine the frequency and analysis of two variables that are thought to be related. Data were processed using SPSS 23.

\section{RESULT AND DISCUSSION}

Table 1. Distribution of Patients by Gender

\begin{tabular}{ccc}
\hline & Frequency (n) & \% \\
\hline Male & 68 & 57,1 \\
Female & 51 & 42,9
\end{tabular}

From the table above, data on the number of male patients are 68 people (57.1\%), and the number of female patients is 51 people $(42.9 \%)$.

Table 2. Distribution of Patients by Age

\begin{tabular}{ccc}
\hline Age & Frequency (n) & \% \\
\hline $0-4$ & 15 & 12,6 \\
$5-9$ & 44 & 37,0 \\
$10-14$ & 46 & 38,7 \\
$15-19$ & 14 & 11,8 \\
\hline
\end{tabular}

From the table above, data is obtained, the age with the most patients is $10-14$ years as many as 46 people (38.7\%), after
5-9 years as 44 people (37\%), 0-4 years as many as 15 people (12.6\%) and at least 14 people aged 15-19 years $(11,8 \%)$.

Table 3. Overview of Bleeding Manifestations

\begin{tabular}{ccc}
\hline $\begin{array}{c}\text { Bleeding } \\
\text { Manifestation }\end{array}$ & Frequency (n) & \% \\
\hline No & 112 & 94,1 \\
Yes & 7 & 5,9
\end{tabular}

From the data above, it can be seen that there were very few bleeding manifestations in Dengue Infection at Cawang UKI Hospital, only seven people (5.9\%), while those who did not experience bleeding were 112 people (94.1\%).

Table 4. Platelet Overview

\begin{tabular}{ccc}
\hline Platelet & Frequency (n) & \% \\
\hline$<50000$ & 23 & 19,3 \\
$50000-$ & 50 & 42,0 \\
100000 & 46 & 38,7 \\
$>100000$ & 4
\end{tabular}

From the data above, it was obtained that there were 23 $(19.3 \%)$ people with $<50000$ platelets, 50 people $(42 \%)$ with $50000-100000$ platelets and 46 people (38.7\%) with $>100000$ platelets.

Table 5. Distribution of DHF Degrees

\begin{tabular}{ccc}
\hline DHF Degrees & Frequency (n) & $\mathbf{\%}$ \\
\hline Dengue Hemorrhagic Fever & 113 & 95,0 \\
Dengue Shock Syndrome & 6 & 5,0
\end{tabular}

The data above showed that DHF was 113 people (95\%) and DSS was 6 people (5\%).

Table 6. Chi-square test

\begin{tabular}{cccc}
\hline Statistical test & Value & df & $\begin{array}{c}\text { Asymptotic Significance } \\
\text { (2-sided) }\end{array}$ \\
\hline Pearson & 56,759 & 2 &, 000 \\
Chi-Square & 46,253 & 2 &, 000 \\
Likelihood Ratio & 35,065 & 1 &, 000 \\
Linear-by-linear Association & 119 & & \\
N of Valid Cases &
\end{tabular}

From the results of the Chi-Square test above, the results obtained are $\mathrm{P}=0.000(\mathrm{P}<0.05)$

Table 7. Platelet Count Crosstabs with DHF Degrees

\begin{tabular}{ccccc}
\hline & & Platelets & Total \\
\cline { 2 - 4 } & $\mathbf{4 5 0 0 0 0}$ & $\mathbf{5 0 0 0 0 - 1 0 0 0 0 0}$ & $\mathbf{1 0 0 0 0 0}$ & 99 \\
\hline DHF & 7 & 48 & 44 & 20 \\
DSS & 16 & 2 & 2 & 119 \\
\hline Total & 23 & 50 & 46 & 20 \\
\hline
\end{tabular}

From the data above, the results obtained with the diagnosis of DHF: platelet count $<50000=7$ people, $50000-100000=48$ people, and $>100000=44$ people. DSS: platelet count $<50000=16$ people, $50000-100000=2$ people, and $>100000=2$ people . 
Table 8. R Correlation Coefficient

\begin{tabular}{cccccc}
\hline & & Value & $\begin{array}{c}\text { Asymptotic } \\
\text { Standardized Error }\end{array}$ & $\begin{array}{c}\text { Approximate } \\
\text { T }\end{array}$ & $\begin{array}{c}\text { Approximate } \\
\text { Significance }\end{array}$ \\
\hline Interval by Interval & Pearson's R &,- 545 &, 080 & $-7,033$ &, $\mathbf{0 0 0}$ \\
Ordinal by Ordinal & Spearman Correlation &,- 506 &, 083 & $-6,350$ &, $\mathbf{0 0 0}$ \\
N of Valid Cases & & 119 & & & \\
\hline
\end{tabular}

From the above results obtained data Pearson's R -0.545. ( $\pm 0.5-0.75$ = strong correlation).

In table 1 , it is known that the most dengue infections in the male sex were 68 people $(57.1 \%)$, while women were 51 people $(42.9 \%)$. This study follows the results of research presented by Bima (2014), which states that dengue infection occurs more in men than women. Boys have a higher morbidity rate than girls, but basically, there is no difference in terms of gender to the morbidity rate of DHF. However, the results of other studies show the same pattern of occurrence ${ }^{16}$ In table 2, it is known that the patients' age with the most dengue infection is $10-14$ years as many as 46 people (38.7\%), after $5-9$ years as 44 people (37\%), $0-4$ years as many as 15 people $(12.6 \%)$ and at least $15-19$ years old as many as 14 people $(11.8 \%)$.

The age of most DHF patients is at the age 5-14 years. Preschool or primary school children (aged 4-12 years) often show a secondary serological response, which helps determine prevention policies. ${ }^{12}$ Based on the Chi-Square test results in Table 4.6, the results obtained $\mathrm{P}=0.000$ (P $<0.05$ ), which means that there is a significant relationship between the number of platelets and the severity of DHF.

This study follows the theory put forward, namely that the formed immune-antibody complex will stimulate platelet aggregation, so that mass degradation of platelets occurs, which causes thrombocytopenia. ${ }^{10}$ In table 7 , it is known that the relationship between the severity of DHF and the platelet count in the diagnosis of DHF: Platelet count $<5000 / \mathrm{mm} 37$ people, 50000-100000/mm3 48 and $>100000 / \mathrm{mm} 344$ people. DSS: Platelet count $<5000 / \mathrm{mm} 316$ people, $50000-$ $100000 / \mathrm{mm} 32$ people, and $>100000 / \mathrm{mm} 32$ people.

In a state of shock (DSS), the platelet count is $<5000 / \mathrm{mm} 3$. It requires us to increase vigilance in patients diagnosed with DHF with a platelet count $<500000 / \mathrm{mm}[3 ; 14]$. From the results of the correlation coefficient $\mathrm{R}$ test in table 8 , Pearson's $\mathrm{R}$ data is -0.545 ( $\pm 0.5-0.75=$ strong correlation), which means that there is a strong correlation between the number of platelets and the severity of DHF and also a negative trend, which means that it is getting heavier. A lower platelet count follows the severity of DHF. These results follow the theory that the heavier the degree of DHF, the lower the platelet count.

\section{CONCLUSION}

Based on the results of the study obtained through the medical records of pediatric patients at Cawang Hospital as many as 119 cases, it can be summarized as follows: a) Based on the results of this study, the highest number of children with dengue infection was male; b) Based on the results of this study, the highest number of children with dengue infection was in the age range of 10-14 years; c) The results of this study found that patients with dengue hemorrhagic fever were not always accompanied by bleeding manifestations such as red spots (petechiae); d) Based on the results of this study, the highest number of pediatric patients with dengue infection was with a platelet range of 50000$100000 / \mathrm{mm} 3$; e) Based on the results of this study, the distribution of the degree of DHF is higher than that of SSD; f) There is a significant relationship between the number of platelets and the severity of DHF; and g) There is a strong and negative correlation between the number of platelets and the severity of DHF.

\section{REFERENCES}

1. Nishiura, Hiroshi, and Scott B. Halstead. "Natural history of dengue virus (denv) -1 and denv-4 infections: reanalysis of classic studies." The Journal of infectious diseases 2007; 195(7):1007-1013. https://doi.org/10.1086/511825

2. Behrmen, R., R. Kliegman, and A. Arvin. "Ilmu kesehatan anak nelson." Jakarta: EGC 2000.

3. Wahyono, Tri Yunis Miko. "Analisis epidemiologi deskriptif filariasis di Indonesia." Buletin Jendela Epidemiologi 2010; 1:914.

4. Soedarto. Demam Berdarah Dengue. Jakarta: Sagung Seto. 2012.

5. Candra, Aryu. "Demam Berdarah Dengue: Epidemiologi, Patogenesis, dan Faktor Risiko Penularan." ASPIRATOR-Journal of Vector-borne Disease Studies 2010; 2(2).

6. Prawono, Dedy Hadi, and Usman Hadi. "Acquired Immunodeficiency Syndrome Patient with A Dengue Hemorrhagic Fever Co-Infection." Indian Journal of Forensic Medicine \& Toxicology 2021; 15(3).

7. Andrew, J., and Ananya Bar. "Morphology and morphometry of Aedes aegypti adult mosquito." Annual Research \& Review in Biology 2013: 52-69.

8. World Health Organization. "Comprehensive guideline for prevention and control of dengue and dengue haemorrhagic fever." 2011.

9. Soedarmo, S. S. P. "Demam Berdarah (Dengue) pada Anak. cet. 2." Jakarta: Penerbit Universitas Indonesia 2005: 26-45.

10. Desai, Varun. "A Study of Clinico--Haematological Profile of Patients with Dengue Fever." PhD diss., Sumandeep Vidyapeeth, 2018.

11. Adam, Frédéric, Alexandre Kauskot, Mathieu Kurowska, Nicolas Goudin, Isabelle Munoz, Jean-Claude Bordet, Jian-Dong Huang et al. "Kinesin-1 is a new actor involved in platelet secretion and thrombus stability." Arteriosclerosis, thrombosis, and vascular biology 2018;

https://doi.org/10.1161/ATVBAHA.117.310373 38(5):1037-1051

12. Martínez Torres, Eric. "Dengue." Estudos avançados 2008; 22:3352. https://doi.org/10.1590/S0103-40142008000300004

13. Chuansumrit, Ampaiwan, and Wathanee Chaiyaratana. "Hemostatic derangement in dengue hemorrhagic fever." Thrombosis research 2014; 133(1):10-16. https://doi.org/10.1016/j.thromres.2013.09.028

14. Huang, Qi, Wen-Qi Cai, Zi-Wen Han, Mo-Yu Wang, Yang Zhou, Jun-Ting Cheng, Ying Zhang et al. "Bispecific T cell engagers and their synergistic tumor immunotherapy with oncolytic viruses." American Journal of Cancer Research 2021; 11(6):2430.

15. World Health Organization. "Comprehensive guideline for prevention and control of dengue and dengue haemorrhagic fever." (2011). 
16. Muller, David A., Alexandra CI Depelsenaire, and Paul R. Young. "Clinical and laboratory diagnosis of dengue virus infection." The Journal of infectious diseases 2017; 215(suppl_2):S89-S95. https://doi.org/10.1093/infdis/jiw649

17. Kamuh, Sitti SP, Arthur E. Mongan, and Maya F. Memah. "Gambaran Nilai Hematokrit dan Laju Endap Darah pada Anak dengan Infeksi Virus Dengue di Manado." eBiomedik 2015; 3(3). https://doi.org/10.35790/ebm.3.3.2015.9517

18. Periayah, Mercy Halleluyah, Ahmad Sukari Halim, and Arman Zaharil Mat Saad. "Mechanism action of platelets and crucial blood coagulation pathways in hemostasis." International journal of hematology-oncology and stem cell research 2017; 11(4):319.

19. Kaplan, Zane S., and Shaun P. Jackson. "The role of platelets in atherothrombosis." Hematology 2010, the American Society of Hematology Education Program Book 2011; 1:51-61. https://doi.org/10.1182/asheducation-2011.1.51

20. Wahab, A. Samik. "Ilmu Kesehatan Anak Nelson." Ed 15 2000: 216. 